\title{
Designing a Model for Optimization of Maintenance and Inspection efforts against Third Party Damage to cross country Pipelines in India
}

\author{
S. S Gupta, A.K. Arya, P Vijay
}

\begin{abstract}
In India there are nearly $45000 \mathrm{~km}$ of cross- country pipelines in operation, safety and reliability of this network of pipelines play a major role in the energy distribution security of the country. A cross country pipeline can fail due to various reasons primary among these are corrosion and third-party damage. In a populous country like India third party damage has emerged as a newest threat to the pipelines, as on date nearly $40 \%$ of all pipeline failures are due to third party damage. Thirdparty damage to an underground pipeline is generally defined as a category of damage caused to the pipeline due to the activities of an outside (other than the pipeline owner or its authorized representative) agency, for example an agency building road across the pipeline right of way may cause rupture of the pipeline due to uncontrolled use of earthmoving equipment. Most of the third-party damages are caused due to ignorance or negligence, as the third-party damage is caused by human error, it does not have any trend and random in nature. Unfortunately, majority of third-party damage leads to severe and instantaneous failure of the pipeline leading to release of highly inflammable content that can cause widespread destruction of life and property. To minimize the possibility of third party damage to a reasonably low rate, it is necessary that maintenance and inspection (M\&I) practices are properly oriented, this is possible only when the weight of the factors responsible for third party damage is known and M\&I programme is designed accordingly. This paper proposes a model for calculating weight of various factors responsible for third party damage and how the model can optimize M\&I efforts as well as build best possible defense against third party damage for an underground high-pressure cross-county hydrocarbon pipeline.
\end{abstract}

Keyword: Third party Damage, Pipelines, Hydrocarbon, M\&I, Optimization

\section{INTRODUCTION}

India is a major consumer of the hydrocarbon energy. 2018 Economic survey of India, projects GDP growth between 7 $-7.5 \%$ in FY19. IMF projects Indian Economy to grow at $7.4 \%$ in 2018 and $7.8 \%$ in 2019. India GDP growth rate is expected to be $8.2 \%$ over 2015 to 2040 period and population is expected to grow at a CAGR of $0.8 \%$ as per Central Statistical Organization, India. Primary Energy demand of India is projected to more than double by 2040; It is expected to grow to 2132 Mtoe in 2040 from 749 Mtoe in 2015. [1]. Demand for energy in India is expected to increase rapidly, even outpacing china over the 2016 - 2040 period
One of the major challenges is in the area of distribution of this energy across the vast nation. The safest mode of transfer of bulk hydrocarbon energy is pipelines. Therefore, India is building its pipeline infrastructure at equally fast pace. Total oil and gas pipeline in India are close to $40,000 \mathrm{~km}$, a conservative estimate indicate that by 2030 the pipeline length will touch $50,000 \mathrm{~km}$ a growth of nearly $30 \%$. However, Total pipeline length is $43807 \mathrm{Km}$ as on 31.3.2018 as against $38458 \mathrm{Km}$ as on 31.3.2013 [2].

Safe and efficient operation of such a large network of pipeline is major challenge, considering India's everincreasing population and fast rate of urbanization. Rate of urbanization is expected to grow quickly with more opportunities and development. As compared to $32 \%$ urbanization in 2015, it is expected to grow to $46 \%$ in 2040 .

\section{SAFETY RECORDS OF PIPELINES}

Global records indicate that in USA from 2004 to 2015, failure frequencies of oil pipelines vary between $0.4 \mathrm{times} / \mathrm{kkm} \cdot \mathrm{yr}$ and $0.6 \mathrm{times} / \mathrm{kkm} \cdot \mathrm{yr}$, which is slightly increasing in the last 5 years as seen in the trend line. As for the natural gas pipelines the number goes up from 0.04 times $/ \mathrm{kkm} \cdot \mathrm{yr}$ to 0.14 times $/ \mathrm{kkm} \cdot \mathrm{yr}$ with vibration. [Analysis and Comparison of Long-Distance Pipeline Failures [3].

As far as Europe is concerned EGIG [8] reports indicate that the primary failure frequency over the entire period (19702013) was equal to $0.33 \mathrm{per} \mathrm{kkm} \cdot \mathrm{yr}$. This is slightly lower than the failure frequency of $0.35 \mathrm{per} \mathrm{kkm} \cdot \mathrm{yr}$ reported in the 8th EGIG report (1970-2010). The primary failure frequency over the last five years was equal to 0.16 per $\mathrm{kkm} \cdot \mathrm{yr}$,

In UK, from 1962 to 2014, altogether 192 leakages have been recorded. The overall failure frequency over the period 1962 to 2014 is 0.219 incidents per kkm.yr, while in the previous report this figure was 0.223 incidents per $\mathrm{kkm} \cdot \mathrm{yr}$ (covering the period from 1962 to 2013).

Sergio B. Cunha [5] indicated that the failure rates of liquid pipelines about twice as that of gas pipelines, on the basis comparison of 5 yearly average of pipeline failures in USA, Canada, UK, Brazil and Europe.

Analysis of major pipeline failure databases indicate that there are 5 major causes of pipeline failures viz.

1. Third Party Damage

2. Corrosion (both external and internal)

3. Material - construction

4. Acts of God

5. Operational Error 


\section{Designing a Model for Optimization of Maintenance and Inspection efforts against Third Party Damage to cross country Pipelines in India}

These data bases indicate that the major cause of pipeline failure is External interference or third-party damage). Causes of pipeline failure in USA for the year 2015 is indicated in the table 1.1 , also cause wise failure of European gas pipelines is indicated in table 1.2. As can be seen from the table 1.2, between 1971 and 2000 nearly 50\% of all pipeline failures are due to third-party activities.

Table 1.1, Pipeline Incident in USA for 2015

\begin{tabular}{|c|l|c|}
\hline S.No. & Cause of Failure & $\begin{array}{c}\% \text { of } \\
\text { failure }\end{array}$ \\
\hline 1 & Corrosion & 18.2 \\
\hline 2 & $3^{\text {rd }}$ Party Damage & 17.1 \\
\hline 3 & Operational Error & 8.3 \\
\hline 4 & $\begin{array}{l}\text { Material } \\
\text { constrn. failure }\end{array}$ & 44.1 \\
\hline 5 & Natural causes & 6.7 \\
\hline
\end{tabular}

Table 1.2, EGIG Pipeline Failure Data 1970-2001[4]

\begin{tabular}{|c|l|c|}
\hline S No. & Incident Cause & 1970-2001 (\%) \\
\hline 1 & $\begin{array}{l}\text { External } \\
\text { Interference }\end{array}$ & 50 \\
\hline 2 & $\begin{array}{l}\text { Construction } \\
\text { Defects/ material } \\
\text { Failure }\end{array}$ & 17 \\
\hline 3 & Corrosion & 7 \\
\hline 4 & Ground Movement & 5 \\
\hline 5 & $\begin{array}{l}\text { Hot tap made by } \\
\text { error }\end{array}$ & 6 \\
\hline 6 & Others & \\
\hline
\end{tabular}

A comparison of cause wise pipeline failures rates given in major data bases for last 5 years was done in paper [5]. The findings are presented in Table 1.3. All these data bases indicate that among all the cause of pipeline failure the leading reason is third party interference.

\section{What is third party damage}

A cross country pipeline is laid at a depth of $1 \mathrm{~m}$ to $1.5 \mathrm{~m}$ below the ground surface, the strip of the ground below which the pipelines are laid are generally referred to pipeline right of way (ROW), such ROWs are supposed to be clearly marked over the ground for ease of identification. Such ground markers are variously placed at $250 \mathrm{~m}$ to $500 \mathrm{~m}$ apart. Sometimes due various human activities such markers are removed (sometimes deliberately or by ignorance) by members of public or by natural causes like floods etc., In such a scenario agencies other than the pipeline operator like road laying agency, power cable operators, other pipeline operators being ignorant (or careless) about presence of a high pressure cross country pipeline in the vicinity, causes damage to the pipeline while carrying out excavation. Such damages, which have the potential to cause complete rupture of the pipeline leads to release of oil or gas leading fire and large-scale destruction of life and property.

The reasons for such predominance of third-party failure among the causes of pipeline failure is not difficult to guess, over the year's corrosion and other such causes of pipeline failure has been contained by adopting improved method and procedures designed for prevention of these reasons. For example, better fabrication practices have reduced failures due to poor fabrication of pipes, improved construction and inspection techniques have reduced probability of error in construction.

Better understanding of pipeline corrosion and development superior quality of pipeline coating, corrosion inhibitors etc. have led to substantial reduction in corrosion of the pipeline. Unfortunately, this was not the case in case of third-party damages, because such damages are caused primarily due to human activity which is unpredictable and random. Analysis of cases of pipeline failure due to third party damage indicate that despite providing all kinds of warning signs about presence of a pipeline a third agency continued to dig in the vicinity of the pipeline in process damaging the pipeline leading to major incidents of fire and explosion.

Table 1.3 - Cause wise Pipeline Failure [5]

\begin{tabular}{|l|c|c|c|c|c|c|c|c|}
\hline Country/ Type & Data Base & $\begin{array}{c}3^{\text {rd }} \\
\text { Party }\end{array}$ & $\begin{array}{c}\text { Internal } \\
\text { Corrosion }\end{array}$ & $\begin{array}{c}\text { External } \\
\text { Corrosion }\end{array}$ & $\begin{array}{c}\text { Material - } \\
\text { construction }\end{array}$ & $\begin{array}{c}\text { Cracking } \\
- \text { SCC }\end{array}$ & $\begin{array}{c}\text { Acts } \\
\text { of } \\
\text { God }\end{array}$ & $\begin{array}{c}\text { Others - } \\
\text { Unknown }\end{array}$ \\
\hline Europe-Gas & EGIG & $48 \%$ & $0.5 \%$ & $13 \%$ & $17 \%$ & $2.5 \%$ & $8 \%$ & $11 \%$ \\
\hline UK- Gas & UKOPA & $22 \%$ & $1 \%$ & $20 \%$ & $28 \%$ & $16 \%$ & $5 \%$ & $8 \%$ \\
\hline USA - Gas & DOT-PRCI & $43 \%$ & $16 \%$ & $14 \%$ & $8 \%$ & $1 \%$ & $10 \%$ & $8 \%$ \\
\hline Brazil-Gas & Tranpetro & $67 \%$ & $0 \%$ & $33 \%$ & $0 \%$ & $9 \%$ & $0 \%$ & $0 \%$ \\
\hline Canada & NEB & $6 \%$ & \multicolumn{2}{|c|}{$25 \%$} & $6 \%$ & $38 \%$ & $6 \%$ & $19 \%$ \\
\hline Europe- Oil & CONCAWE & $42 \%$ & $5 \%$ & $12 \%$ & $29 \%$ & $2 \%$ & $3 \%$ & $7 \%$ \\
\hline USA - Oil & DOT-API & $41 \%$ & $10 \%$ & $32 \%$ & $14 \%$ & $0 \%$ & $3 \%$ & $0 \%$ \\
\hline Brazil -Oil & Transpetro & $23 \%$ & $8 \%$ & $49 \%$ & $10 \%$ & $0 \%$ & $8 \%$ & $2 \%$ \\
\hline
\end{tabular}


Another important observation about third party damage is that it takes places mostly in urban areas, where human activities are more intense. The prime reason behind third party damage is random digging in the vicinity of the pipeline by agencies like cable operator, power line operators, sewer line operators, foreign pipeline crossing etc., such activities are naturally more in the urban and industrialized areas there fore incidents of failure from third party damage is more in urban areas. This this regards data collected fore UK indicate that failure rate of pipelines due to third party damage in nearly three times higher in urban areas than in the rural areas.

Table 1.4: Failure Frequencies per $1000 \mathrm{~km}$ per geographical areas [6]

\begin{tabular}{|l|l|l|}
\hline S. No & Locality & $\begin{array}{l}\text { Frequency } \\
\text { failure } / 1000 \mathrm{~km}\end{array}$ \\
\hline 1 & Urban & 0.66 \\
\hline 2 & Rural & 0.25 \\
\hline
\end{tabular}

[Based on CONCAWE report 1971-1996]

\section{Third Party Damage - Indian Scenario}

One of the major challenges while taking up any study on Indian pipeline failure is poor availability of data on pipeline incidents, generally pipeline operating companies are reluctant to share such data on their own, Oil Industry Safety Directorate (OISD), a body established under the aegis of Ministry of Petroleum \& Natural Gas ( MOP\&G) had in the past made some attempts to come out with some sort of pipeline failure data but in the absence of any mandatory requirement the initiative was not successful and only after couple of years the data generation process seem to have died a natural death. In the recent year Petroleum and Natural Gas Regulatory Board (PNGRB), a body established under an act of Indian Parliament, has been making effort to organize such pipeline failure data and hopefully in future useful data would be available, but availability of pipeline failure data is still insufficient, and no study can be based on the quantity of data available. In such a scenario, the only option left is to rely on databases maintained by International bodies like PHSMA, USA, UKOP, UK, EGIG, Europe and CONCAWE, Europe.

A review of the majority of the papers published by various authors across the world in reputed journals, codes and applicable standards and data bases and reports on pipeline failure published by EGIG [15] on European gas pipelines and CONCAWE [16] on European liquid pipelines, reports of National Energy Board (NEB), Canada and documents published by PHMSA and National Transportation Safety Board (NTSB), USA indicate that third party damage has emerged as leading cause of pipeline failure.

There are research works on pipeline risk which are focused primarily to determine probability of failure and consequence of failure arising out of different reasons like corrosion, 3rd party damage, construction \& manufacturing defect etc. One of the works by Alex Dawotola [13] in 2012, does touches upon the risk of pipeline failure from third party damage under the backdrop of socio-economic scenario of Nigeria. Another significant research work by L.Parvizsedghy [14] deals extensively on pipeline risk and

proposes a maintenance model based on risk analysis, the author considers techniques like Bow-Tie analysis, Artificial Neural Network (ANN), Fuzzy Set theory, General theory of uncertainty, Monte-Carlo Simulation and Neuro-Fuzzy etc. Author proposes a comprehensive model for quantifying risk of a pipeline failure from factors like corrosion, acts of god and third-party damage, but specific focus was not on third party damage. During late nineties to early 2000, Dey et.al.[15,16] had done couple of studies on pipeline risk analysis under the backdrop of Indian pipeline scenario, In their work Dey et.al [16] evaluated the risk of failure of different segments of a cross-country pipeline and developed strategies for the selection of the inspection techniques for such pipelines using Analytic Hierarchy Process (AHP) technique. This model applied expert opinion to obtain the weight of variables that were identified to contribute to the failure of pipelines. Variables were categorized as risk factors that included external and internal corrosion, construction and material defects, as well as acts of God. In another work Dey et.al [16] proposed a riskbased maintenance model considering off-shore pipelines, the model had the provisions for considering expert opinion to obtain relative weight of various factors responsible for pipeline failure, however, the approach adopted to capture expert opinion was subjective in nature. The proposed model by Dey et.al [16] suggest inspection tools based on experience. Unfortunately, relevancy of such studies under Indian context has greatly diminished primarily due to incumbency of regulatory regime and enhanced public awareness with the development of Industrial scenario in India over last one and half decade.

Studies done by others like Xinhong Li et.al. and C Zhang et.al. [20,23] on quantification of pipeline risk using Bayesian theory also considers nearly all factors of pipeline failure and not specific to third party damage. Besides, absence of any specific study on development of model exclusive to third party damage to pipeline majority of the related studies are designed to establish the robustness of the models proposed based on the one or other techniques chosen by the authors. From the point of view of pipeline operators, the party most effected by third party damage to their pipelines, such model hardy meets their expectation and ground realities, especially in a country like India, where socio-economic scenario is different from the one prevailing in say, China. To sum up, the approach in majority of the studies are to formulate a model but no real attempt was made to establish the validity of such models on ground. Though some of studies do provide directional assistance towards further studies in the field. While, very few researchers have tried to examine the significance of Third-Party Interference related damage to cross country pipeline, one exception is the work done by Jun Li et.al. [19]. This work does attempt to assess the probability of third-party damage to pipeline in real terms, unfortunately, the study is confined to urban pipeline network only rather than cross-country pipeline. Another work of significance on third party damage to gas pipeline by Zeyang Qiu, et.al. 


\section{Designing a Model for Optimization of Maintenance and Inspection efforts against Third Party Damage to cross country Pipelines in India}

[21], in this papers authors emphasizes on development of a quantitative risk assessment model against 3rd party damage to gas pipelines. Authors use Analytical Hierarchy Process (AHP) and Fuzzy Comprehensive Evaluation to quantify the weight of each of the factors responsible for 3rd party damage and calculate their importance. The authors, however, did not attempt to validate the model on any gas pipeline or pipeline system. The work though provides valuable insight into the process of development of model for assessing probability of 3rd party damage to a pipeline.

This work is taken up considering i) growing network of pipelines in India ii) rapid development of Indian economy leading to heightened human activates iii) growth of population in the areas close to pipeline and iv) rapid urbanization, and v) no study has been done till date on the probability of pipeline damage in India due to third party interference. The propose model does consider the reality of Indian scenario through expert opinion, to ensure that the model does possess desired level of robustness, multicriteria decision support techniques AHP [22] is adopted at the core of the model under the consideration that AHP is probably one of the best technique for determination of relative weight of factors consequently, to a large extent negate the lack of availability data and can accommodate expert opinion.

For Indian pipelines not much organized data is available, limited quantity of data on distribution pipelines, collected from PNGRB archives indicate that third party activity is one of the leading causes of pipeline failure. Out of total 58 failures as many as 28 are due to third party activities which is $52 \%$ of all failures [Table 1.5]. Due to fast growth of population and rapid urbanization and pace of building new pipelines, to bring down the rates of third-party damage to pipelines, Indian pipeline industry must overcome significant hurdles.

The model proposed is research is likely to quantify weight of the factors responsible for third party damage to a pipeline based on the data pertaining to the pipeline itself. The ultimate objective of this work is to guide (through the proposed model) the pipeline operator to design his Maintenance \& Inspection (M\&I) programme in a manner that possibility of third-party damage is reduced. Additionally, the designers of new pipelines can also learn from the model and accordingly take corrective action in the design (and construction) stage itself so that possibility of third-party damage remains low in all future times in the pipeline's operational life.

While there are studies that are like this paper [13.14], however, model proposed in these studies did not consider human factor. As mentioned elsewhere above, human behaviour plays a huge role [12] as far as third-party damage is concerned, therefore, whatever model is built, it is preferable that human opinion/ experience is built into the model to make it as realistic as possible. One of the ways to meet this requirement is to call upon the experience of the pipeline experts and built their opinion into the model.
Table 1.5, Pipeline Failures in India [7]

\begin{tabular}{|l|l|l|c|c|}
\hline \multirow{2}{*}{ S.No } & \multicolumn{2}{|c|}{ Period } & \multicolumn{2}{c|}{ No. of Failure } \\
\cline { 2 - 5 } & From & To & Total & $3^{\text {rd }}$ Party \\
\hline 1 & Dec 13 & Dec 14 & 8 & 5 \\
\hline $\mathbf{2}$ & Dec 14 & Mar 15 & 5 & 7 \\
\hline $\mathbf{3}$ & Apr 15 & Jun 15 & 12 & 7 \\
\hline $\mathbf{4}$ & Oct 15 & Mar 16 & 18 & 5 \\
\hline $\mathbf{5}$ & Apr 16 & Jun 16 & 11 & 4 \\
\hline
\end{tabular}

\section{Factors Responsible for Third Party damage}

A review of major international data base $[8,9]$ on pipeline failure, standards like ASME B31.4, OISD-214 and PNGRB- T4S etc., relevant articles by pipeline experts that handle the subject of pipeline failure in great details and analyses data pertaining to pipeline over a period of more than 40 years, Mather et.al 2002[10], Horalek, 2006[4], Chaplin and Howard 2015[11], Hopkins, 2005 [6], Jackson et.al.[12]. Also information provided in Pipeline and Hazardous Materials Safety Administration (PHMSA), USA data base, National Transportation Safety Board, USA, Failure Investigation Report - Central Florida Pipeline 10inch Jet Fuel Pipeline Failure,2012 and National Energy Board ( NEB) reports indicate that major factors of third party damage can be clubbed into following 5 factors:
1. Depth of Cover
2. Population Density
3. Land use pattern
4. Wall thickness of pipe
5. Public Awareness Level

\section{DESIGNING A MODEL TO QUANTIFY FACTORS OF THIRD-PARTY DAMAGE}

For the present work a $135 \mathrm{~km}$ long Indian pipeline is selected. The pipeline is 10 " in diameter and has a wall thickness of 0.219", in certain stretches like waterway crossings road crossing, highly populated areas the wall thickness used varies of 0.312 " to 0.435 ". The pipeline is engaged in transportation of petroleum product. The maximum operating pressure of the pipeline is $77 \mathrm{~kg} / \mathrm{cm}^{2}$. The pipeline is designed according to the provision of Oil Industry Safety Directorate (OISD) standard OISD-214 (which is equivalent to ASME B 31.4). This pipeline has 7 mainline valves located at random distance stating from originating station to the final terminal as indicated in figure 1.1

These 5 factors are further divided into sub-factors [fig 1.2] that are the controlling variables upon which the significance of primary factors largely depends. The factors and their corresponding sub-factors can be seen from Figure 1.2

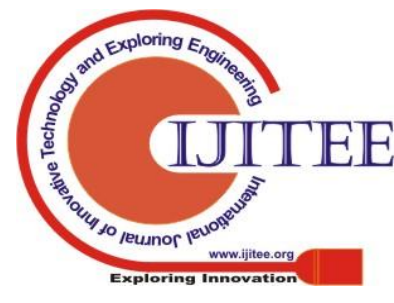


There are 17 sub-factors in total, these sub-factors are connected to the parent factors as indicted in fig 1.2. Subsector against each of the factors are the ones on whom the characteristic behaviour of the primary

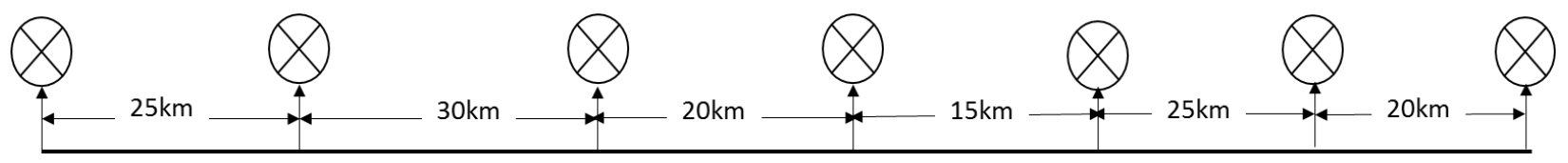

Fig.1.1, Six segment of the pipeline

factors depend. The spread of the sub-factors is captured in terms of length in $\mathrm{km}$. for the pipeline section considered for this study, table 1.6 indicate segment wise distribution of sub-factors

Values shown in Table 1.6, against each of the sub-factors (all values are in $\mathrm{km}$.) means the pipeline stretch in $\mathrm{km}$, where a particular sub-factor is present, for example in segment 6, [refer Fig.1.1] for factor population density, sub- factor $>500$ has a value of 8 this means over a length of $8 \mathrm{~km}$ of the pipeline (in segment 6) has a population density of more than 500 persons/sq.km (one $250 \mathrm{~m}$ either side of the pipeline right of way). A second example, for the factor Depth of Cover, sub-factor $<1 \mathrm{~m}$, segment 1 , the value indicated is 2 , in Table 1.6, this mean over a length of $2 \mathrm{~km}$ (may not be in a continuous stretch) of pipeline, the depth of cover is less than $1 \mathrm{~m}$.

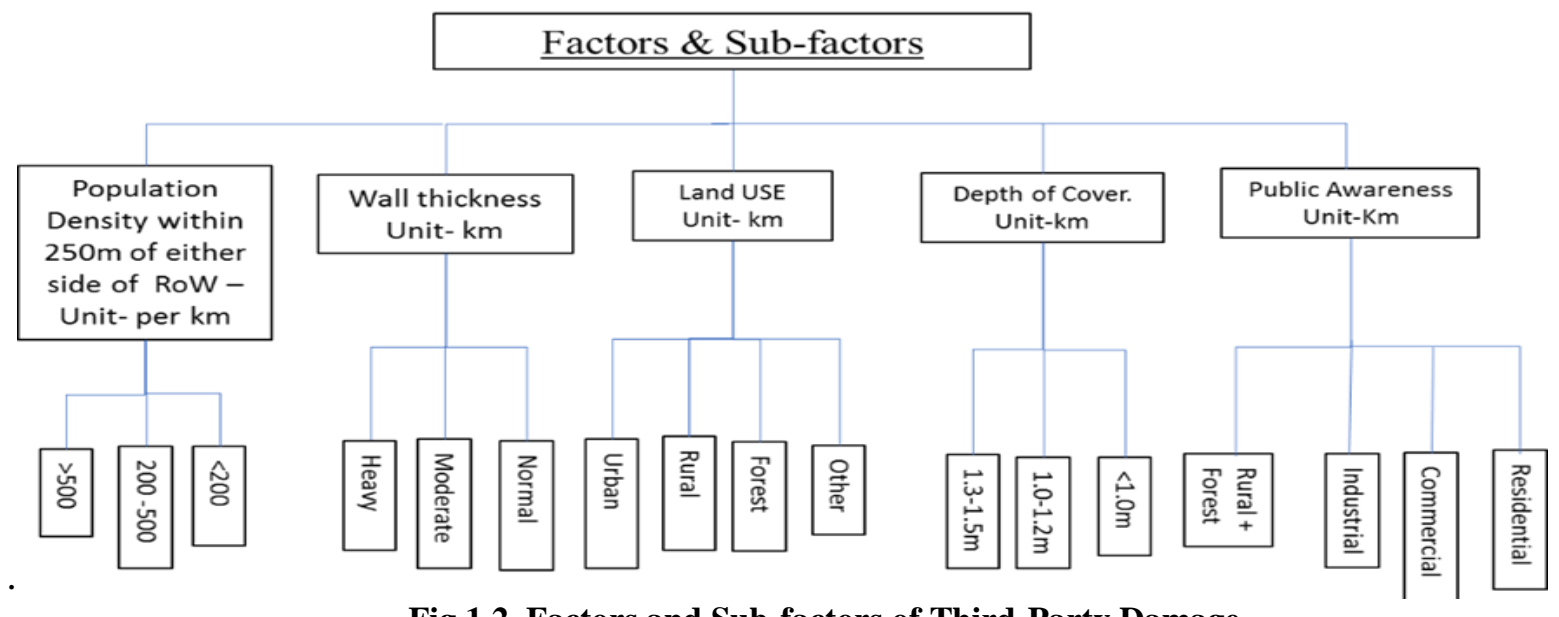

Fig 1.2, Factors and Sub-factors of Third-Party Damage

Table 1.6 - Segment wise stretch length for each factor and their sub-factors.

\begin{tabular}{|c|c|c|c|c|c|c|c|}
\hline \multirow[t]{2}{*}{ Factor } & \multirow[t]{2}{*}{ Sub-factors } & \multicolumn{6}{|c|}{ Segment } \\
\hline & & $1=25 \mathrm{~km}$ & $2=30 \mathrm{~km}$ & $3=20 \mathrm{~km}$ & $4=15 \mathrm{~km}$ & $5=25 \mathrm{~km}$ & $6=20 \mathrm{~km}$ \\
\hline \multirow{3}{*}{$\begin{array}{l}\text { Population } \\
\text { Density } \\
\text { (PD) }\end{array}$} & $>500$ & 11 & 7 & 19 & 5 & 6 & 8 \\
\hline & $200-500$ & 6 & 20 & 7 & 8 & 14 & 9 \\
\hline & $<200$ & 8 & 3 & 3 & 1 & 1 & 3 \\
\hline \multirow{3}{*}{$\begin{array}{l}\text { Wall } \\
\text { thickness }\end{array}$} & Heavy & 3 & 6 & 4 & 0 & 5 & 0 \\
\hline & Moderate & 2 & 6 & 0 & 0 & 6 & 0 \\
\hline & Normal & 20 & 18 & 16 & 15 & 14 & 20 \\
\hline \multirow[t]{4}{*}{ Land Use } & Urban & 19 & 6 & 5 & 1 & 10 & 3 \\
\hline & Rural & 4 & 20 & 14 & 14 & 8 & 16 \\
\hline & Forest & 2 & 4 & 0 & 0 & 2 & 0 \\
\hline & Others & 0 & 0 & 1 & 0 & 5 & 1 \\
\hline \multirow{2}{*}{$\begin{array}{l}\text { Depth of } \\
\text { Cover (DC) }\end{array}$} & $1.3-1.5 \mathrm{~m}$ & 5 & 7 & 5 & 2 & 3 & 1 \\
\hline & $1-1.2 \mathrm{~m}$ & 18 & 23 & 14.5 & 13 & 22 & 19 \\
\hline
\end{tabular}


Designing a Model for Optimization of Maintenance and Inspection efforts against Third Party Damage to cross country Pipelines in India

\begin{tabular}{|l|l|c|c|c|c|c|c|}
\hline & $<1 \mathrm{~m}$ & 2 & 0 & 0.5 & 0 & 0 & 0 \\
\hline \multirow{3}{*}{$\begin{array}{l}\text { Public } \\
\text { Awareness }\end{array}$} & Rural+ Forest & 6 & 24 & 5 & 10 & 5 & 16 \\
\cline { 2 - 8 } & Industrial & 3 & 0 & 4 & 0 & 5 & 0 \\
\cline { 2 - 8 } & Commercial & 2 & 1 & 2 & 1 & 5 & 2 \\
\cline { 2 - 8 } & Residential & 14 & 5 & 9 & 4 & 10 & 2 \\
\hline
\end{tabular}

To determined segment wise weight of each factor expert opinion is considered in a scale of 0 to 9 , four experts were told to award marks (in a scale of 0-9, based on the significance of the factors and their experience).

Experts were selected through a process as indicated in fig 1.3 below. The experts are evaluated against 4 criteria i)
Source of Knowledge (SK), ii) Source of Experience (SE), iii) Source of Information (SI) and iv) Source of Bias (SB). These 4 criteria are further divided into sub-criteria for the purpose of marking. Expert marking scale is indicated in table 1.7. For each of these 4 parameters marks are awarded in line with the marking criteria indicated in table 1.7.

Table 1.7, Marking Scale for Experts

\begin{tabular}{|c|c|c|c|c|c|c|}
\hline \multirow[t]{2}{*}{ SK } & Q & $>P G$ & PG & G & $<G$ & \multirow{2}{*}{$\begin{array}{l}Q=\text { Qualification, PG-Post Graduate, G=Gradua te, } \\
\text { M=Marks } \\
\text { SK= Source of Knowledge }\end{array}$} \\
\hline & Marks & 7 & 5 & 3 & 1 & \\
\hline \multirow[b]{2}{*}{$\mathbf{S E}$} & Years & $>20$ & $15-20$ & $10-15$ & $<10$ & \multirow{2}{*}{$\begin{array}{l}\text { Years of experience } \\
\mathrm{SE}=\text { Source of Experience }\end{array}$} \\
\hline & Marks & 7 & 5 & 3 & 1 & \\
\hline \multirow[b]{2}{*}{ SI } & Source & $\mathrm{F}+\mathrm{T}$ & $\bar{F}$ & $\mathrm{~T}$ & $\mathrm{UN}$ & \multirow{2}{*}{$\begin{array}{l}\mathrm{F}=\text { Field, } \mathrm{T}=\text { Theoretical, UN=Not Known } \\
\text { SI=S curce of Information }\end{array}$} \\
\hline & Marks & 7 & 5 & 3 & 1 & \\
\hline \multirow[t]{2}{*}{$\mathbf{S B}$} & Ser erity & $\mathrm{VL}$ & $\mathrm{L}$ & $\mathrm{M}$ & $\overline{\mathrm{H}}$ & \multirow{2}{*}{$\begin{array}{l}\text { VL=Very Low, L=Low, M=Medium, H=High, SB= } \\
\text { Source of Bias }\end{array}$} \\
\hline & Marks & 7 & 5 & 3 & 1 & \\
\hline
\end{tabular}

\section{Expert Selection Process}

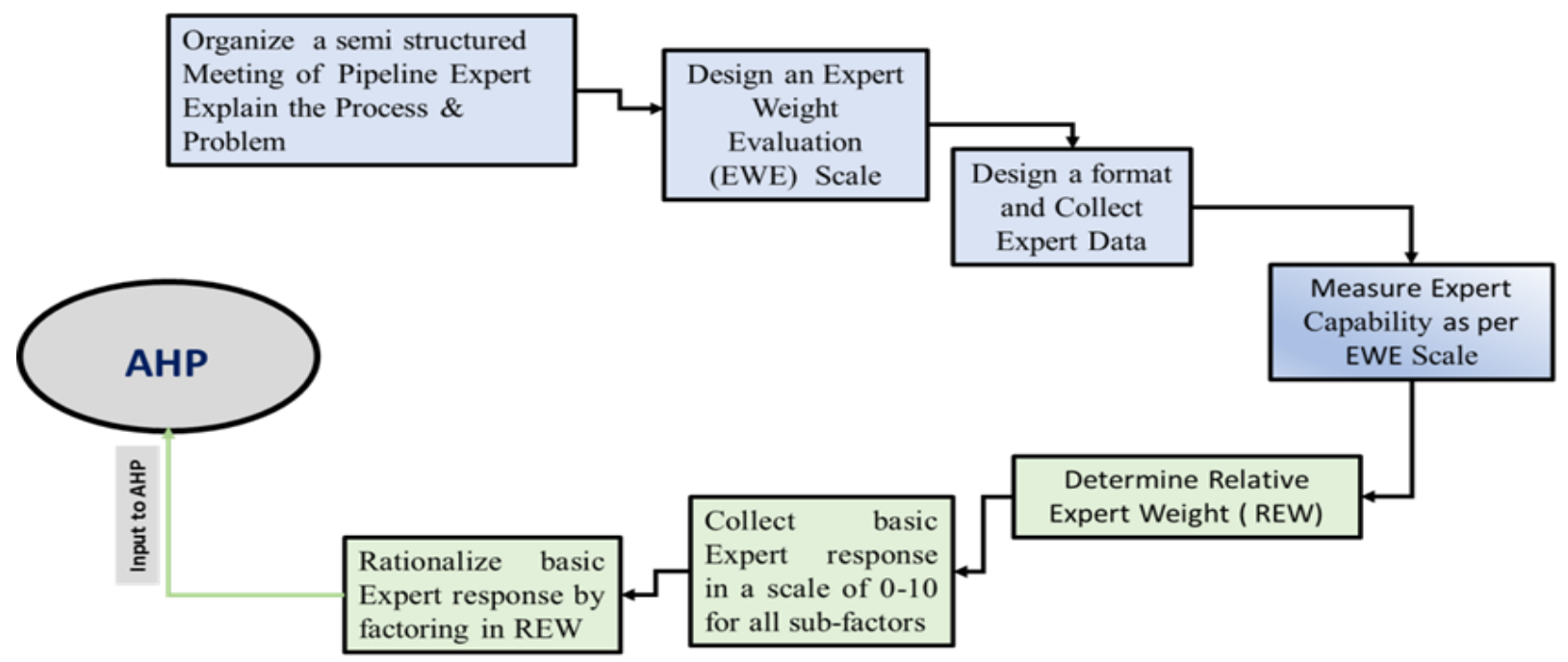

Fig 1.3, Expert Selection Process

From a group of 20 experts, 4 highest scoring experts are selected. For rationalization purpose, the weight of top expert is considered as 1 and rest of 3 experts are weighted corresponding to their individual marks w.r.t to the marks scored by topmost expert. For example, if the top expert score 25 , then 25 is considered to carry a weight of 1 , the second highest expert scores, say 20, his weight shall be determined as $(20 / 25) \times 1=0.80$, in this manner weight of all 4 experts are determined. The weight of all 4 experts are designated as Relative Expert Weight (REW) 


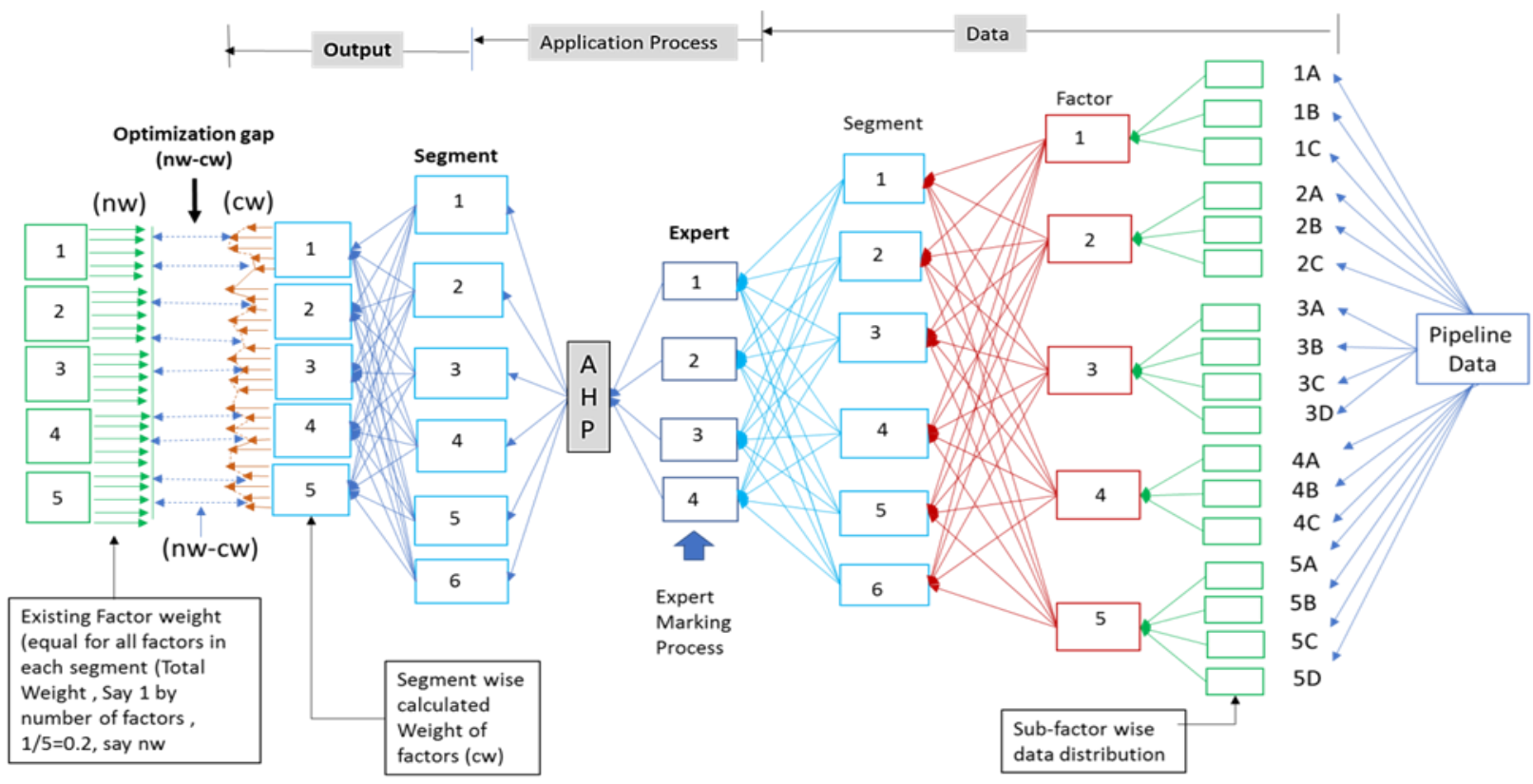

Fig 1.4. Model for Determining Relative Weight of Factors responsible for Third Party Damage to a Pipeline

One of the key elements of expert selection process is capturing experts experience against the 4 criteria viz. SK, SI, SE and SB mentioned above. For this purpose, a format has been designed as indicated in figure 1.5, expert data collected in the format is used to provide marks (refer table 1.7) to each expert.

Top 4 experts are asked to put marks as they deem fit in a scale of 0-9 against each sub factor. The marks given by expert 1 (top expert) is take as it is but that by other 3 experts are factored in with their respective REW. The marks thus awarded by each expert is multiplied by length of that sub-factor to get an overall score for the said factor for a segment by an expert. This exercise is done for all 6 segments for all 5 factors by all 4 experts. The overall model is represented by fig 1.4 . The model depicts the input, the process and the output.

Table 1.8 is the basic table where values against each subfactor for all 6 segments are awarded by expert 1, it is important 2 note that marks given by expert 1 is taken as it is as REW for expert $1=1$. Whereas for table 1.9 marked by expert 2, the marks are rationalized by factoring in with REW of Expert 2 which is 0.92

\begin{tabular}{|c|c|c|c|}
\hline \multicolumn{4}{|c|}{ Relative Expert Weight (REW) scale } \\
\hline Expert1 & Expert 2 & Expert 3 & Expert 4 \\
\hline 1 & 0.92 & 0.85 & 0.77 \\
\hline
\end{tabular}


Designing a Model for Optimization of Maintenance and Inspection efforts against Third Party Damage to cross country Pipelines in India

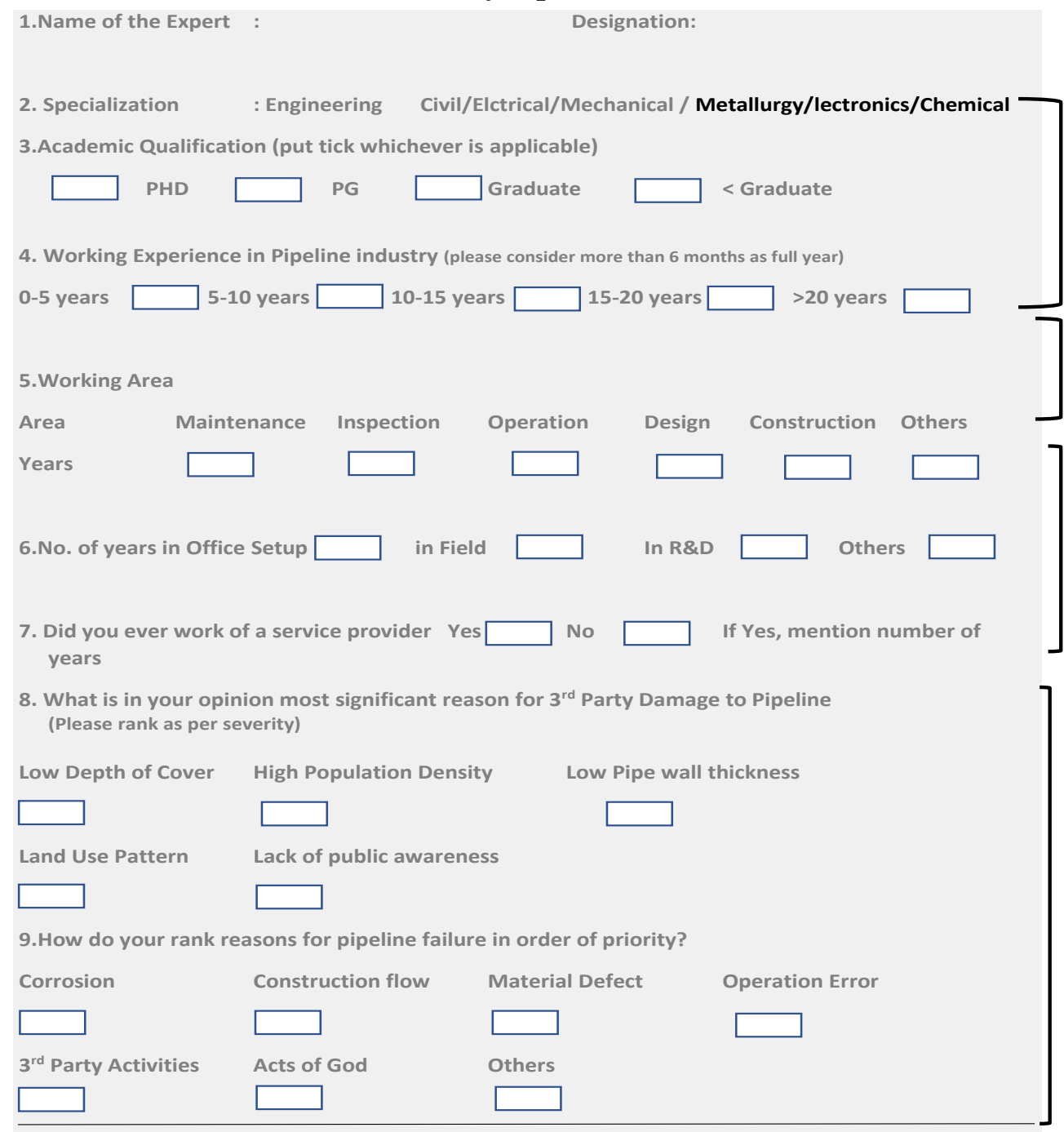

Fig. 1.5, Expert Data collection Format

Table 1.8, Marks awarded by Expert 1

\begin{tabular}{|c|c|c|c|c|c|c|c|c|c|c|c|c|c|c|c|c|c|c|}
\hline Basic Mark & Expert 1 & 7 & 5 & 1 & 3 & 4 & 7 & 8 & 3 & 1 & 3 & 1 & 3 & 7 & 3 & 7 & 7 & 5 \\
\hline \multicolumn{2}{|c|}{ Normalised NExpert 1} & 7.00 & 5.00 & 3.00 & 1.00 & 3.00 & 7.00 & 7.00 & 3.00 & 1.00 & 3.00 & 3.00 & 7.00 & 9.00 & 3.00 & 5.00 & 5.00 & 7.00 \\
\hline Pipeline & Length & \multicolumn{3}{|c|}{ Population Density per $/ \mathrm{km}$ in km } & \multicolumn{3}{|c|}{ Wall Thickness (Km) } & \multicolumn{4}{|c|}{ Land Use (Km) } & \multicolumn{3}{|c|}{ Depth of Cover (km) } & \multicolumn{4}{|c|}{ Public Awareness level (Km) } \\
\hline Segment & $\mathrm{km}$ & $>500$ & $200-500$ & $<200$ & Heavy & Mod. & Normal & Urban & Rural & Forest & Others & $1.3-1.5 \mathrm{~m}$ & $1 \mathrm{~m}-1.2 \mathrm{~m}$ & $<1 \mathrm{~m}$ & Rural+forest & Industrial & Commercial & Residential \\
\hline \multirow{2}{*}{1} & 25 & 11 & 6 & 8 & 3 & 2 & 20 & 19 & 4 & 2 & 0 & 5 & 18 & 2 & 6 & 3 & 2 & 14 \\
\hline & Score & 77.00 & 30.00 & 24.00 & 3.00 & 6.00 & 140.00 & 133.00 & 12.00 & 2.00 & 0.00 & 15.00 & 126.00 & 18.00 & 18.00 & 15.00 & 10.00 & 98.00 \\
\hline \multirow{2}{*}{2} & 30 & 7 & 20 & 3 & 6 & 6 & 18 & 6 & 20 & 4 & 0 & 7 & 23 & 0 & 24 & 0 & 1 & 5 \\
\hline & Score & 49.00 & 100.00 & 9.00 & 6.00 & 18.00 & 126.00 & 42.00 & 60.00 & 4.00 & 0.00 & 21.00 & 161.00 & 0 & 72.00 & 0.00 & 5.00 & 35.00 \\
\hline \multirow{2}{*}{3} & 20 & 10 & 7 & 3 & 4 & 0 & 16 & 5 & 14 & 0 & 1 & 5 & 14.5 & 0.5 & 5 & 4 & 2 & 9 \\
\hline & Score & 70.00 & 35.00 & 9.00 & 4.00 & 0.00 & 112.00 & 35.00 & 42.00 & 0.00 & 3.00 & 15.00 & 101.50 & 0 & 15.00 & 20.00 & 10.00 & 63.00 \\
\hline \multirow{2}{*}{4} & 15 & 5 & 8 & 1 & 0 & 0 & 15 & 1 & 14 & 0 & 0 & 2 & 13 & 0 & 10 & 0 & 1 & 4 \\
\hline & Score & 35.00 & 40.00 & 3.00 & 0.00 & 0.00 & 105.00 & 7.00 & 42.00 & 0.00 & 0.00 & 6.00 & 91.00 & 0.00 & 30.00 & 0.00 & 5.00 & 28.00 \\
\hline \multirow{2}{*}{5} & 25 & 6 & 18 & 1 & 5 & 6 & 14 & 10 & 8 & 2 & 5 & 3 & 22 & 0 & 5 & 5 & 5 & 10 \\
\hline & Score & 42.00 & 90.00 & 3.00 & 5.00 & 18.00 & 98.00 & 70.00 & 24.00 & 2.00 & 15.00 & 9.00 & 154.00 & 0.00 & 15.00 & 25.00 & 25.00 & 70.00 \\
\hline \multirow{2}{*}{6} & 20 & 8 & 9 & 3 & 0 & 0 & 20 & 3 & 16 & 0 & 1 & 1 & 19 & 0 & 16 & 0 & 2 & 2 \\
\hline & Score & 56.00 & 45.00 & 9.00 & 0 & 0 & 140.00 & 21.00 & 48.00 & 0 & 3.00 & 3.00 & 133.00 & 0.00 & 48.00 & 0 & 10.00 & 14.00 \\
\hline
\end{tabular}


Table 1.9, Marks awarded by Expert 2

\begin{tabular}{|c|c|c|c|c|c|c|c|c|c|c|c|c|c|c|c|c|c|c|}
\hline Basic Mark & Expert 2 & 3 & 5 & 7 & 7 & 5 & 3 & 3 & 5 & 7 & 4 & 7 & 3 & 1 & 3 & 7 & 7 & 5 \\
\hline REW Marks & Expert 2 & 2.76 & 4.60 & 6.44 & 6.44 & 4.60 & 2.76 & 2.76 & 4.60 & 6.44 & 3.68 & 6.44 & 2.76 & 0.92 & 2.76 & 6.44 & 6.44 & 4.60 \\
\hline Pipeline & Length & \multicolumn{3}{|c|}{ Population Density per $/ \mathrm{km}$ in km } & \multicolumn{3}{|c|}{ Wall Thickness (Km) } & \multicolumn{4}{|c|}{ Land Use $(\mathrm{Km})$} & \multicolumn{3}{|c|}{ Depth of Cover $(\mathrm{km})$} & \multicolumn{4}{|c|}{ Public Awareness level (Km) } \\
\hline Segment & $\mathrm{km}$ & $>500$ & $200-500$ & $<200$ & Heavy & Mod. & Normal & Urban & Rural & Forest & Others & $1.3-1.5 \mathrm{~m}$ & $1 \mathrm{~m}-1.2 \mathrm{~m}$ & $<1 \mathrm{~m}$ & Rural+forest & \begin{tabular}{|l|} 
Industrial \\
\end{tabular} & Commercial & Residential \\
\hline \multirow{2}{*}{1} & 25 & 11 & 6 & 8 & 3 & 2 & 20 & 19 & 4 & 2 & 0 & 5 & 18 & 2 & 6 & 3 & 2 & 14 \\
\hline & Score & 30.36 & 27.60 & 51.52 & 19.32 & 9.20 & 55.20 & 52.44 & 18.40 & 12.88 & 0.00 & 32.20 & 49.68 & 1.84 & 16.56 & 19.32 & 12.88 & 64.40 \\
\hline \multirow{2}{*}{2} & 30 & 7 & 20 & 3 & 6 & 6 & 18 & 6 & 20 & 4 & 0 & 7 & 23 & 0 & 24 & 0 & 1 & 5 \\
\hline & Score & 19.32 & 92.00 & 19.32 & 38.64 & 27.60 & 49.68 & 16.56 & 92.00 & 25.76 & 0.00 & 45.08 & 63.48 & 0 & 66.24 & 0.00 & 6.44 & 23.00 \\
\hline \multirow{2}{*}{3} & 20 & 10 & 7 & 3 & 4 & 0 & 16 & 5 & 14 & 0 & 1 & 5 & 14.5 & 0.5 & 5 & 4 & 2 & 9 \\
\hline & Score & 27.60 & 32.20 & 19.32 & 25.76 & 0.00 & 44.16 & 13.80 & 64.40 & 0.00 & 3.68 & 32.20 & 40.02 & 0 & 13.80 & 25.76 & 12.88 & 41.40 \\
\hline \multirow{2}{*}{4} & 15 & 5 & 8 & 1 & 0 & 0 & 15 & 1 & 14 & 0 & 0 & 2 & 13 & 0 & 10 & 0 & 1 & 4 \\
\hline & Score & 13.80 & 36.80 & 6.44 & 0.00 & 0.00 & 41.40 & 2.76 & 64.40 & 0.00 & 0.00 & 12.88 & 35.88 & 0.00 & 27.60 & 0.00 & 6.44 & 18.40 \\
\hline \multirow{2}{*}{5} & 25 & 6 & 18 & 1 & 5 & 6 & 14 & 10 & 8 & 2 & 5 & 3 & 22 & 0 & 5 & 5 & 5 & 10 \\
\hline & Score & 16.56 & 82.80 & 6.44 & 32.20 & 27.60 & 38.64 & 27.60 & 36.80 & 12.88 & 18.40 & 19.32 & 60.72 & 0.00 & 13.80 & 32.20 & 32.20 & 46.00 \\
\hline \multirow{2}{*}{6} & 20 & 8 & 9 & 3 & 0 & 0 & 20 & 3 & 16 & 0 & 1 & 1 & 19 & 0 & 16 & 0 & 2 & 2 \\
\hline & Score & 22.08 & 41.40 & 19.32 & 0 & 0 & 55.20 & 8.28 & 73.60 & 0 & 3.68 & 6.44 & 52.44 & 0.00 & 44.16 & 0 & 12.88 & 9.20 \\
\hline
\end{tabular}

Once the marks are allotted by all 4 experts the total marks scored by each factor for a segment is added and divided by the segment length to get marks per $\mathrm{km}$. The marks are rationalized considering marks scored by factor Depth of Cover $(\mathrm{DC})=1$. With respect to DC weight of other factors are determined as indicated in table 1.11 (for segment 1 , expert 1) as relative score. The relative scores are pairwise compared using Analytica Hierarchy Process (AHP) to get the get the average weight of each of the 5 factors for an expert. In the similar manner average weight of the 5 factors are determined for all 4 experts for a segment and finally for all 6 segments. These average weights will give relative importance of various factors in all the segments individually. To determined relative weight of factors for the entire pipeline average weight of all segments for all experts needs to be synthesized.
Once the relative weight of all 5 factors are determined the pipeline owner can adjust the existing Maintenance \& Inspection (M\&I) Programme according to the weight of the factors. For example, if factor Depth of Cover (DC) carries highest relative weight among the 5 factors for a segment or for the entire pipeline the owner may choose to increase the frequency of DC survey from the current frequency. Table 1.10A $1.10 \mathrm{~B}, 1.10 \mathrm{C}$ and 1.10D indicate the steps followed to get the result (weight) of factors. Final step is to synthesize the weight again each factor given by 4 experts and determine the average weight. For the purpose of this paper results of expert 1 is presented in table 1.11. Similar tables are developed for rest of the 5 segments and final synthesized weight of all factors are determined for all 6 segments (entire pipeline) which is presented in Table 1.12.

Table 1.10A, Segment wise Summary of Marks Scored by Factors, for Expert 1

\begin{tabular}{|c|c|c|c|c|c|c|c|c|}
\hline \multirow{2}{*}{ Factors } & \multicolumn{9}{|c|}{ Segment } & \multicolumn{2}{c|}{ Total } & Average \\
\cline { 2 - 9 } & $\mathbf{1}$ & $\mathbf{2}$ & $\mathbf{3}$ & $\mathbf{4}$ & $\mathbf{5}$ & $\mathbf{6}$ & Score & Score \\
\hline \hline PD & 131.00 & 158.00 & 114.00 & 78.00 & 135.00 & 110.00 & 726.00 & 121.00 \\
\hline LU & 147.00 & 106.00 & 80.00 & 49.00 & 111.00 & 72.00 & 565.00 & 94.17 \\
\hline WT & 149.00 & 150.00 & 116.00 & 105.00 & 121.00 & 140.00 & 781.00 & 130.17 \\
\hline AL & 141.00 & 112.00 & 108.00 & 63.00 & 135.00 & 72.00 & 631.00 & 105.17 \\
\hline DC & 159.00 & 182.00 & 116.50 & 97.00 & 163.00 & 136.00 & 853.50 & 142.25 \\
\hline Total & 727.00 & 708.00 & 534.50 & 392.00 & 665.00 & 530.00 & 3556.50 & 26.34 \\
\hline Segment Length, Km & 25 & 30 & 20 & 15 & 25 & 20 & 135 & 22.50 \\
\hline Score/km & 29.08 & 23.60 & 26.73 & 26.13 & 26.60 & 26.50 & 26.34 & 26.43 \\
\hline
\end{tabular}


Designing a Model for Optimization of Maintenance and Inspection efforts against Third Party Damage to cross country Pipelines in India

Table 1.10 B; Summary of Segment 1, Length 25km, Marks by Expert 1

\begin{tabular}{|l|c|c|c|}
\hline \multirow{2}{*}{ Factors } & \multicolumn{1}{|c|}{ Expert } & Score & Relative \\
\cline { 2 - 5 } & \multicolumn{1}{c|}{ Score } & Per km & Score \\
\hline Depth of Cover & 159.00 & 6.36 & 1 \\
\hline Population Density & 131.00 & 5.24 & 0.82 \\
\hline Awareness Level & 141.00 & 5.64 & 0.89 \\
\hline Wall Thickness & 149.00 & 5.96 & 0.94 \\
\hline Land Use & 147.00 & 5.88 & 0.92 \\
\hline
\end{tabular}

Table 1.10 C, Basic Matrix (segment 1)

\begin{tabular}{|c|c|c|c|c|c|}
\hline Factor & DC & PD & AL & WT & LU \\
\hline DC & 1 & 1.21 & 1.13 & 1.07 & 1.08 \\
\hline PD & 0.82 & 1 & 1.08 & 1.14 & 1.12 \\
\hline AL & 0.89 & 0.93 & 1 & 1.06 & 1.04 \\
\hline WT & 0.94 & 0.88 & 0.95 & 1 & 0.99 \\
\hline LU & 0.92 & 0.89 & 0.96 & 1.01 & 1 \\
\hline Total & 4.57 & 4.91 & 5.11 & 5.27 & 5.23 \\
\hline
\end{tabular}

Table 1.10D, Normalized Matrix

\begin{tabular}{|c|c|c|c|c|c|c|}
\hline Factor & DC & PD & AL & LU & WT & Avg \\
\hline DC & 0.2187 & 0.2470 & 0.2207 & 0.2023 & 0.2067 & $\mathbf{0 . 2 1 9 1}$ \\
\hline PD & 0.1802 & 0.2035 & 0.2107 & 0.2156 & 0.2144 & $\mathbf{0 . 2 0 4 9}$ \\
\hline AL & 0.1939 & 0.1891 & 0.1957 & 0.2003 & 0.1992 & $\mathbf{0 . 1 9 5 7}$ \\
\hline WT & 0.2050 & 0.1789 & 0.1852 & 0.1896 & 0.1885 & $\mathbf{0 . 1 8 9 4}$ \\
\hline LU & 0.2022 & 0.1814 & 0.1877 & 0.1922 & 0.1911 & $\mathbf{0 . 1 9 0 9}$ \\
\hline & 1 & 1 & 1 & 1 & 1 & 1 \\
\hline
\end{tabular}

Table 1.11, Segment wise summary - Relative Weight of Factors (for Expert 1)

\begin{tabular}{|c|c|c|c|c|c|c|c|}
\hline \multirow{2}{*}{ Factors } & \multicolumn{9}{|c}{ Segment } & \multicolumn{2}{c|}{ Average } \\
\cline { 2 - 8 } & 1 & 2 & 3 & 4 & 5 & 6 & Expert 1 \\
\hline DC & 0.219 & 0.262 & 0.221 & 0.259 & 0.246 & 0.269 & 0.246 \\
\hline PD & 0.205 & 0.164 & 0.182 & 0.169 & 0.180 & 0.162 & 0.177 \\
\hline AL & 0.196 & 0.200 & 0.188 & 0.192 & 0.180 & 0.211 & 0.194 \\
\hline WT & 0.189 & 0.168 & 0.180 & 0.150 & 0.192 & 0.147 & 0.171 \\
\hline LU & 0.191 & 0.207 & 0.229 & 0.231 & 0.203 & 0.211 & 0.212 \\
\hline
\end{tabular}

Table1.12, Synthesized Expert Score for the entire pipeline

\begin{tabular}{|c|c|c|c|c|c|}
\hline \multirow{2}{*}{ Factors } & \multicolumn{4}{|c|}{ Expert } & \multirow{2}{*}{$\begin{array}{c}\text { All Expert } \\
\text { Average }\end{array}$} \\
\cline { 2 - 5 } & $\mathbf{1}$ & $\mathbf{2}$ & $\mathbf{3}$ & $\mathbf{4}$ & 0.247 \\
\hline DC & 0.246 & 0.179 & 0.205 & 0.180 & $\mathbf{0 . 2 1 9}$ \\
\hline PD & 0.177 & 0.193 & 0.186 & 0.189 & $\mathbf{0 . 1 9 8}$ \\
\hline AL & 0.194 & 0.206 & 0.201 & 0.204 & $\mathbf{0 . 2 0 4}$ \\
\hline WT & 0.171 & 0.225 & 0.218 & 0.181 & $\mathbf{0 . 1 9 5}$ \\
\hline LU & 0.212 & 0.197 & 0.190 & & \\
\hline
\end{tabular}


Table 1.13, Existing vs Calculated Weight

\begin{tabular}{|c|c|c|c|c|}
\hline A & B & $\mathrm{C}$ & D & $\mathbf{E}$ \\
\hline Factors & $\begin{array}{l}\text { All Expert Average } \\
\text { factor weight }\end{array}$ & $\begin{array}{c}\text { Uniform factor } \\
\text { weight }\end{array}$ & GAP (C-D) & $\begin{array}{c}\text { Percentage Variation } \\
E=(D / C) \times 100\end{array}$ \\
\hline DC & 0.219 & 0.20 & -0.019 & $-9.58 \%$ \\
\hline PD & 0.184 & 0.20 & 0.016 & $8.05 \%$ \\
\hline $\mathbf{A L}$ & 0.198 & 0.20 & 0.002 & $1.19 \%$ \\
\hline WT & 0.204 & 0.20 & -0.004 & $-2.21 \%$ \\
\hline $\mathbf{L U}$ & 0.195 & 0.20 & 0.0050 & $2.56 \%$ \\
\hline
\end{tabular}

The model explained above to determine the relative weight of the 5 factors primarily responsible for probable thirdparty damage to a pipeline is compared with the existing system where all the 5 factors are given equal importance. In the current system total Probability $=1$, Number of factors $=5$, Weight of each factor is $1 / 5=02$.

Present M\&I programme is designed based on equal contribution by each factor, whereas the proposed model can calculate the actual contribution for the factors. The difference between the existing weight and calculated weight can be considered as gap in optimization, gap is indicated in table 1.13. Percentage variation indicated in table 1.13 quantifies the additional attention needed by a factor for example factor DC has variation of (-)9.8\% means current level of attention given (in the M\&I Programme) to DC is nearly $10 \%$ less than what it deserves to keep the probability of third-party damage at a level envisaged at the design stage of the pipeline. A positive variation means more than required attention is given to a factor, therefore, there is a scope for reduction in M\&I efforts.

\section{CONCLUSION}

Prevention of third-party damage has emerged as a major challenge to pipeline operators, as third-party damages are manmade and random, no clear engineering solution for all the cases exists. Need is to provide a maintenance and inspection net that can contain most of the causes of thirdparty damage within a reasonable limit. To achieve this objective primary requirement is identification of pipeline wise factors responsible for third party damage and their quantification. Once quantified, the resources deployed to control third party damage can be optimized to obtain maximum benefits from such deployment. The proposed model presents an option that is likely to help the pipeline owner capable of measuring the weight of an impact factor responsible for third party damage and orient existing Maintenance \& Inspection Programme accordingly, to achieve a relatively lower probability of a pipeline damage from third party activities. The proposed model can be further fine tune through application of advance machine learning process, wherein the proposed model can be trained over a larger data base to provide most accurate results.

\section{Biography}

About the authors: S S Gupta is working with Indian Oil Corporation Ltd (Pipelines Division) in the capacity of Chief General Manager (M\&I).

Dr Adarsh Kumar Arya and Dr. P. Vijay are in the teaching faculty in the department of Chemical Engineering, University of Petroleum and Energy Studies, Dehradun, India

\section{References}

1. Report of working group of MoP\&NG on enhancing refinery capacity by 2040, Jan 2018]

2. Indian Petroleum and Natural Gas Stastistics-2015-16, Ministry of Petroleum \& Natural Gas, Govt. Of India

3. Lianshuang Dai et.al. Journal of Petroleum Engineering, Volume 2017, Article ID 3174636.

4. Vladimir Horalek, Safety Performance Determined the Acceptability of Gas Transmission System EGIG Pipeline Incident Data Base, 2004

5. Sérgio B. Cunha, Petrobras Transporte - TRANSPETRO, Comparison and analysis of pipeline failure statistics, Proceedings of the 2012 9th International Pipeline Conference, IPC2012, September 24-28, 2012, Calgary, Alberta, Canada

6. Dr. Phil Hopkins, High design factor pipelines: Integrity issues -Key consideration to decided appropriate pipeline design factor to achieve higher levels of integrity, Journal of Integrity, Penspen 2005.

7. PNGRB Archives on Pipeline Incidents, Petroleum \& Natural Gas Regulatory Board, India.

8. EGIG, Gas pipeline incidents, 10th report of the European Gas Pipeline Incident Data Group (Period 1970 - 2016), 2018

9. CONCAWE Report 6/18, Performance of European cross-country oil pipelines, Statistical summary of reported spillages in 2016 and since 1971, March 2018

10. John Mather, Chris Blackmore, Andrew Petrie \& Charlotte Treves, An assessment of measures in use for gas pipelines to mitigate against damage caused by third party activity, WS Atkins Consultants Ltd. CONTRACT RESEARCH REPORT 372/2001

11. Zoe Chaplin and Kate Howard, Update of pipeline failure rates for land use planning assessments, Health and Safety Laboratory, 2015

12. Christopher Jackson*, Ali Mosleh, Oil and Gas Pipeline Third Party Damage (TPD) - A New Way to Model External Hazard Failure B. John Garrick Institute for the Risk Sciences, University of California, Los Angeles, United States*, Sept 2018

13. Alex Dawotola, Risk Based Maintenance of Petroleum Pipelines, Delft University of Technology, The Netherlands. Doctoral Thesis, 201267.

14. Laya Parvizsedghy, Risk-Based Maintenance Planning Model for Oil and Gas Pipelines, A Thesis in the Department of Building, Civil and Environmental Engineering, Concordia University, Montreal, Quebec, Canada, 2015

15. Dey, P.K. Analytic Hierarchy Process Analyses risk of operating cross-country petroleum pipelines in India, Hazards Review, Vol. 4, Issue 4, pp 213-222, 2003

16. Dey, P. K., Ogunlana S.O., Gupta S.S. \& Tabucanon M.T, A riskbased maintenance model for cross country pipelines, Journal of cost engineering, Vol.40. No.4, [1998], pp24-31.

17. EGIG, Gas pipeline incidents, 10th report of the European Gas Pipeline Incident Data Group (Period 1970 - 2016), 2018

18. CONCAWE Report 6/18, Performance of European cross-country oil pipelines, Statistical summary of reported spillages in 2016 and since 1971, March 2018 
Designing a Model for Optimization of Maintenance and Inspection efforts against Third Party Damage to cross country Pipelines in India

19. Xinhong Li, Guoming, Chen Hongwei Zhu, Quantitative risk analysis on leakage failure of submarine oil and gas pipelines using Bayesian network, Process Safety and Environmental Protection, Volume 103, Part A, September 2016, Pages 163-173

20. Jun Li, Hong Zhang, Yinshan Han, Baodong Wang, Study on Failure of Third-Party Damage for Urban Gas Pipeline Based on Fuzzy Comprehensive Evaluation, 2016, (online), https://doi.org/10.1371/journal.pone.0166472

21. Zeyang Qiu, Wei Liang, Xue Wang,Yang Lin and Meng Zhang, Study on quantitative risk assessment model of the third party damage for natural gas pipelines based on fuzzy comprehensive assessment, 12th International Conference on Damage Assessment of Structures IOP Publishing, 2017

22. T L Satty, Fundamentals of decision-making process and priority theory with the analytical hierarchy process, Vol-VI, e-book second edition, 2013

23. C Zhang, T X Qin, B Jiang and C Huang, A comprehensive probabilistic analysis model of oil pipelines network based on Bayesian network, IOP Conf. Series: Earth and Environmental Science, 2018. 